Discussion

Papers

The Effect of a Leniency Rule on Cartel Formation and Stability: Experiments with Open Communication 
Opinions expressed in this paper are those of the author(s) and do not necessarily reflect views of the institute.

IMPRESSUM

(C) DIW Berlin, 2019

DIW Berlin

German Institute for Economic Research

Mohrenstr. 58

10117 Berlin

Tel. +49 (30) $89789-0$

Fax +49 (30) $89789-200$

http://www.diw.de

ISSN electronic edition 1619-4535

Papers can be downloaded free of charge from the DIW Berlin website:

http://www.diw.de/discussionpapers

Discussion Papers of DIW Berlin are indexed in RePEc and SSRN:

http://ideas.repec.org/s/diw/diwwpp.html

http://www.ssrn.com/link/DIW-Berlin-German-Inst-Econ-Res.html 


\title{
The effect of a leniency rule on cartel formation and stability: experiments with open communication*
}

\author{
Maximilian Andres ${ }^{\dagger} \quad$ Lisa Bruttel ${ }^{\ddagger} \quad$ Jana Friedrichsen ${ }^{\S}$
}

November 29, 2019

\begin{abstract}
Cartels can severely harm social welfare. Competition authorities introduced leniency rules to destabilize existing cartels and hinder the formation of new ones. Empirically, it is difficult to judge the success of these measures because functioning cartels are unobservable. Existing experimental studies confirm that a leniency rule indeed reduces cartelization. We extend these studies by having a participant in the role of the competition authority actively participating in the experiment. Based on chat communication content and price setting behavior, this authority judges whether firms formed a cartel and decides on fines in real time. We find that a leniency rule does not affect cartelization in this setup.
\end{abstract}

JEL-codes: C92, D43, L41

Keywords: cartels, corporate leniency programs, Bertrand competition, experiments

This paper has been updated as DP 1926

*We are indebted to Tobias Lettl and Jonathan Beel for providing us with regular advice from a legal perspective. Further, we thank Pio Baake, Maria Bigoni, Sander Onderstal, and Gyula Seres as well as conference and seminar audiences at Barcelona (EARIE 2019), Leipzig (VfS 2019), Vienna (WU), Essen (Sozialwissenschaftlicher Ausschuss), Berlin (DIW Berlin), and Potsdam (PRSE) for helpful comments. Luis Koch, Fenja Meinecke, Juri Nithammer, and Max Padubrin provided excellent research support. We gratefully acknowledge financial support from the German Research Foundation (DFG), Grants BR 4180/3-1 and FR 3996/1-1. This project, including the design and hypotheses, was preregistered at OSF before data collection had started (osf.io/ubhz8).

$\dagger$ Universität Potsdam

$\ddagger$ Universität Potsdam

${ }^{\S}$ DIW Berlin and Humboldt-Universität zu Berlin 


\section{Introduction}

Competition authorities in Europe, the United States, and other countries can grant cartel members fine reductions if they deliver information that helps the authority to uncover the cartel and fine other cartel members (OECD, 2012). These "leniency," "amnesty," or "bonus" rules are supposed to destabilize cartels and deter the formation of new ones by making deviations from an existing agreement more attractive and by sowing distrust among the cartelists. Competition authorities argue that these leniency rules are proven very successful in deterring cartels. As proof of their claim, they often point to an increasing numbers of convicted cartels. However, an increasing number of convictions may also result from an increasing number of cartels given a constant or even decreasing share of detected ones, making this proof of success questionable. Indeed, perverse effects of the leniency rule are possible because the leniency rule has an option value that reduces the expected future fine (see Motta and Polo (2003)) and because reporting may be used to threaten potential deviators.

Empirical studies evaluating leniency programs struggle with the fact that undetected cartels are unobserved. ${ }^{1}$ Thus, experimental studies are called for, where both detected and undetected cartels are observed by the researcher. In this paper, we propose a new experimental design that allows for distinguishing between innocuous communication and illegal anticompetitive conduct. Using this design, we revisit the question whether a leniency rule effectively reduces cartelization.

Previous experimental studies on the effectiveness of leniency rules approach the question with a number of designs that share the following feature: firms cast votes on whether or not to form a cartel and communication takes place only if all have agreed to form a cartel. The competition authority in these studies is simulated by the computer program. If a control takes place and all firms voted for forming a cartel, they have to pay fines. These studies find that fewer cartels are formed, more cartels are reported, and average market prices are lower with a leniency rule than without it. These results have been found in three player one-shot Bertrand price competition (Apesteguia et al., 2007) and in repeated price competition with three players and homogeneous-goods (Hinloopen and Soetevent, 2008) and two players with differentiated goods (Bigoni et al., 2012, 2015). ${ }^{2}$

\footnotetext{
${ }^{1}$ Brenner (2009) does not find evidence that the EU leniency program was effective whereas the estimations by Ormosi (2014) suggest that the introduction of a leniency rule in the EU at least had a small impact on cartel detection rates. Miller (2009) finds that the US leniency program is effective in deterring cartel formation.

${ }^{2}$ Relatedly, Hinloopen and Onderstal (2014) compare the effectiveness of a leniency rule in first-price auctions, which are isomorphic to homogeneous-goods Bertrand price-setting games, and English auctions with three participants. In their experiment, law enforcement is effective in first-price auctions but the leniency program does not significantly improve law enforcement and tends to have perverse effects in that it reduces the winning bid and makes cartels more stable. However, the number of reported cartels increased with the leniency rule. This observation indicates that the number of revelations is not a suitable measure of the effectiveness of the leniency program. Further experimental studies focus on the
} 
Apart from the one-shot interaction in Apesteguia et al. (2007), these experiments use repeated interactions with structured price communication. ${ }^{3}$ In contrast to the above, Dijkstra et al. (2018) combines repeated homogeneous-goods Bertrand duopolies with free-form chat communication at the beginning of each round if firms agreed to communicate. In line with the idea that communication fosters trust and improves coordination, Dijkstra et al. (2018) find that a leniency program does not significantly decrease cartel incidence but that it only defers the formation of cartels.

In these studies, the vote on communication(=cartel formation) alone determines the risk of being fined; the content of communication and the actual price-setting are not reflected in the fines. ${ }^{4}$ This aspect of the design may strongly influence the decision to communicate because firms may vote against communication to avoid the risk of being fined. This might bias the results on the effectiveness of the leniency rule for two reasons. First, a single firm can veto communication and, thus, cartel formation in its market. As a consequence, a relatively small increase in the number of firms opting against communication will result in an over-proportional decline in cartels being formed. Indeed, Hinloopen and Soetevent (2008) report that such "near unanimity" situations are especially frequent in the leniency treatment while the total share of firms wishing to form a cartel is not different across their two treatments with and without leniency policy. Second, by deciding against communication, a firm also hinders the evolution of mutual trust in its market that may result from chatting. A low level of trust then provides an environment in which a leniency rule turns out to be particularly effective because this rule intends to create distrust by making deviations relatively more attractive (see also Dijkstra et al., 2018).

Our paper addresses both of the mentioned concerns by disentangling cartel formation and communication using an innovative experimental design that includes the human judgment of communication and competitive conduct. Furthermore, our design allows us to analyze how a leniency rule affects the way firms communicate with each other.

In our design, firms interact repeatedly and a chat window opens automatically at the beginning of each round so that communication may always take place. Therefore, no individual firm can entirely block communication in its market. Further, the decision to chat as such does not imply being fined but the content of communication matters. Each market includes a participant in the role of the competition authority as an active player. Whenever a control takes place, this experimental competition authority reads the

exclusion of cartel ringleaders from amnesty (e.g. Bigoni et al., 2012; Hesch, 2012; Wandschneider, 2014; Clemens and Rau, 2019) or on the effect of private damage claims (Bodnar et al., 2019). See (Marvão and Spagnolo, 2014, 2018) for more detailed overviews of these and further studies on cartels and leniency.

${ }^{3}$ Firms iteratively enter acceptable price ranges (Hinloopen and Soetevent, 2008) or directly enter their minimum acceptable price (Bigoni et al., 2012, 2015). In contrast, firms can engage in free-form chat communication for ten minutes in the one-shot framework by Apesteguia et al. (2007).

${ }^{4}$ In the analysis of cartel formation, the price setting is sometimes taken as an additional criterion. 
written free-form chat communication of the experimental firms, observes price setting, and decides about the fines for each firm, such that fines are positively correlated to the severity of the firm's violation of the law. Decisions of the competition authority are incentivized properly by paying the participant in this role in proportion to the overlap between their judgments and those of an expert cartel lawyer, who judges communication content and prices after the experiment.

In this experimental design, communication is allowed as long as it does not serve the purpose of coordinating prices. Thus, firms can generate trust by communicating without risking a fine if they chat about innocuous topics. Irrespective of the presence of a leniency rule, such trust may facilitate tacit collusion, thus reducing the need for explicit cartel formation. ${ }^{5}$ Moreover, the evolution of trust might counteract the destabilizing effect of a leniency rule that intends to undermine trust among cartel members. ${ }^{6}$

In contrast with previous experimental evidence, where the decision to communicate was equated with the formation of a cartel, we find a leniency rule to be ineffective. The frequency of cartel formation, self-reports, and prices do not differ between the two treatments with and without a leniency rule. Thus, we contribute to the literature on cartel formation and stability our observation that a leniency rule may not improve competition law enforcement when firms can decide to collude more or less explicitly and communication is always possible, as is arguably the case in many industries. Further, we contribute to understanding cartel recidivism. Previous studies assume that a cartel mechanically breaks down after having been fined. However, firms may continue to set non-competitive prices after the control without communicating again (see Harrington Jr, 2004), and, technically, this may be a cartel (see the discussion in Harrington Jr, 2017) but not count as such in the experiments. In previous experimental studies, where a cartel could be fined only if it had communicated since the last control, participants actually used this loophole by early communicating that they would continue to set cartel prices without communicating again after a control took place (see Dijkstra et al., 2018; Bodnar

\footnotetext{
${ }^{5}$ Previous experiments support the idea that communication builds trust in similar environments. Fonseca and Normann $(2012,2014)$ find that communication facilitates collusion in experimental Bertrand markets. Moreover, industries continue to collude tacitly when communication is disabled (hysteresis). Similarly, Gomez-Martinez et al. (2016) find that communication helps the firms to coordinate in a differentiated oligopoly experiment with information about competitors' actions, where the same information would result in more competitive behavior in the absence of communication. Experiments by Harrington Jr et al. (2016) show that free-text communication is more effective in supporting collusive outcomes than structured price announcements, especially in markets with more than two firms or with asymmetries.

${ }^{6}$ The leniency policy increases the "strategic risk" (Marvão and Spagnolo, 2018) from forming a cartel. Spagnolo (2004) provides some theoretical considerations into this direction, but a rigorous formal treatment or experimental analysis of the trust channel with respect to leniency rules and cartel deterrence, to our best knowledge, does not exist. However, several papers provide theoretical and experimental evidence that higher "strategic risk" - understood as a lower sucker's payoff-reduces cooperation in repeated prisoner's dilemma games (Blonski et al., 2011; Breitmoser, 2015; Dal Bó and Fréchette, 2018) such that a deterring effect on cartel formation should be expected.
} 
et al., 2019). ${ }^{7}$ Our setting with an active competition authority enables us to sanction agreed-upon cartels, in line with legal practice, even if no new communication took place since the last control.

We also contribute to the literature on the relationship between communication and collusion. In particular, we investigate how a leniency rule affects the way firms communicate with each other, which expands this literature as most existing studies in this field did not include any law enforcement. Consistent with the null effect in terms of economic outcomes, we find the communication content to be surprisingly similar in the two treatments. We attribute the observed ineffectiveness of the leniency rule to the trustenhancing effects of unrestricted communication and an improved evaluation of what does or does not constitute a cartel. Dijkstra et al. (2018), the only other study on the leniency rule with free-form communication we are aware of, also finds no evidence that communication is affected by the leniency rule. However, in their design the expected fine only depends on the decision to communicate and not on the chat content, so that this observation is less surprising.

In the following, we describe our experimental design in Section 2 and develop hypotheses in Section 3. We then present the experimental results in Section 4 and provide a discussion of them in Section 5. We conclude in Section 6.

\section{Experimental design and procedures}

In the experiment, participants are matched into groups of four. Each group represents a market, in which three participants take the role of firms and a fourth participant takes the role of the competition authority. Each group interacts for at least 25 rounds as described below. Role assignments and matching groups remain fixed throughout the experiment.

Structure of each round In each round except the first one, participants in the role of firms can communicate in free form chat for 60 seconds before price setting. The chat window opens automatically without firms voting for communication beforehand. ${ }^{8}$ In each round, including the first one, firms choose prices in a discrete Bertrand price-setting game with differentiated products as detailed in Appendix A. The design of the price-setting game and the payoff function for the firms are an adapted three-player version of the setup used by Bigoni et al. (2012). This yields a price of three as the Nash equilibrium price

\footnotetext{
${ }^{7}$ Dijkstra et al. (2018) find strong hysteresis in prices, to the extent that post-cartel prices in the leniency treatment are no lower than cartel prices. This observation indicates that participants indeed continue to collude (tacitly) after the detection of a cartel but that this remains undetected by the automated competition authority.

${ }^{8}$ Communication starts only from the second round on because we use the price level in the first round as a benchmark for price setting in the absence of communication.
} 
and a price of nine as the joint profit maximizing price of the stage game. The firms are informed about each others' prices immediately after the price setting stage. Firms can self-report their market to the competition authority during price setting and then again when they receive the feedback about each other's prices. ${ }^{9}$ Reporting is not possible after an investigation has started.

After the price-setting has ended, a control may take place. It can either be caused by report of a firm as mentioned above or randomly with $10 \%$ probability in each round. ${ }^{10}$ If a control takes place, the participant in the role of the authority gets access to the history of chats and prices in his or her group then makes a judgment about the duration of a potential cartel. He or she also decides about the extent of fines $(0 \%, 50 \%$, or $100 \%)$ for each of the three firms that will be applied to the firms' profits from the cartel. The profit to which the fine is applied is calculated by the experimental program based on the authority's input regarding the duration of the cartel and the firms' profits during the rounds that have passed since the last control.

At the end of each round, participants receive feedback about their own and the other two firms' prices, their own profit, and - if applicable - the results of a control, i.e. the reporting behavior and penalties for all firms in their market.

Repetition and termination rule Participants interact for a minimum of 25 rounds. Starting from round 25, the game ends with the respective round with a probability of $1 / 3$; with the complementary probability of $2 / 3$ the game continues for another round. Thus, participants interact for 27 rounds in expectation. The random termination rule serves the purpose of blurring the time horizon to minimize endgame effects. We informed participants in the instructions that we would stop the experiment after 2.5 hours if the random continuation mechanism had not stopped it before. This event did not occur.

Payment During the experiment, participants receive payoffs in points. The final payoff is converted to euros at an exchange rate of 1 euro $=125$ points for payment at the end of the experiment.

Participants in the role of firms are paid their cumulative earnings from the entire interaction. Perfectly competitive behavior, i.e. playing the Nash equilibrium of the stage game across all rounds, would yield an expected 2700 points and symmetric joint profit maximization would yield 4860 points in expectation. Participants in the role of a firm receive their payment from the experiment as well as a show-up fee of 5 euros immediately after the experiment in cash.

\footnotetext{
${ }^{9}$ As Bigoni et al. (2012) argue, making reporting possible at these two different instances allows to distinguish between reports with the intention to punish another firm's deviation from a cartel agreement (during feedback) and self-reports in order to pre-empt such punishment (during price setting).

${ }^{10}$ According to Ormosi (2014), $10 \%$ constitutes a lower bound of the annual cartel detection rate in the European Union between 1985 and 2009.
} 
Participants in the role of the competition authority are paid based on the overlap of their judgment with the judgment of an expert in competition law with whom we contracted to independently evaluate the chat messages and the price setting behavior of the firms. ${ }^{11}$ For each control, the competition authority takes four decisions (the size of fine for firms 1, 2, and 3, and the duration of the cartel). For each correct decision, i.e., agreement with the expert, these participants receive 900 points. Thus, in each control, they can earn up to 3600 points. Their final payment is the average over the points they achieve per control across all controls that they took part in. In case no control ever takes place in his or her group, the respective authority receives a payoff of 15 euros. Participants in the role of the competition authority receive their payment 2-3 weeks after the experiment by bank transfer. Additionally, they receive a show-up fee of 10 euros immediately after the experiment in cash.

Treatments We ran two treatments in a between-subjects design that varied the presence of a leniency rule at the session level: in the Fine treatment, no amnesty is granted to any firm. In the LENIENCY treatment, the first firm reporting receives full amnesty from fines. ${ }^{12}$

Procedures In the pre-registration, we included a power analysis and specified a target sample size of 24 groups per treatment to be collected in 10 to 12 sessions à 12 to 20 subjects. We collected our actual data in 12 experimental sessions à 12 to 20 subjects that took place in the experimental laboratories at the University of Potsdam and at TU Berlin in February and March 2019. We balanced the sessions per treatment across the two involved laboratories. ${ }^{13}$ Our final sample consists of 23 groups in the Fine treatment and 27 groups in the LENIENCY treatment. On average, the experiment lasted for about 2 hours and participants earned 31.97 euros including the show-up fee.

Participants were given detailed instructions ${ }^{14}$ at the beginning of the experiment, which describe the structure of the interaction, the impact of own and others' prices on profits on the basis of a profit table, and the determination of penalties. Participants are not given the exact mathematical formula according to which profits depend on the

\footnotetext{
${ }^{11}$ The expert is a $\mathrm{PhD}$ student writing a dissertation in the field of competition law and also has practical experience in this area.

${ }^{12}$ Spagnolo (2008) argues that it is important to grant amnesty only to the first reporting firm and not to later applicants. Also Harrington Jr (2008) argues that, in most cases, leniency should be granted only to the first reporting firm. Only for the case of a budget-constrained competition authority-which is not an issue in our experiment-Harrington Jr and Chang (2015) conclude that, in order to detect as many cartels as possible, the authority should award amnesty to all firms providing information helping to convict the cartel.

${ }^{13}$ Participants are required to be proficient in German, but may ignore this and still sign up. Our preregistration specified that a group of participants would be excluded from the analysis if the experimenter detected during the experiment or during payment that at least one participant in the respective group is not proficient in German. This led us to exclude two groups from the Fine treatment.

${ }^{14}$ An English translation of the instructions is contained in Appendix C.
} 
three firms' prices (see Appendix A for details). In addition, participants in the role of an authority were given an information sheet that explains in detail when firm behavior is to be considered as illegal cartel formation and how the duration of the cartel is to be determined (see Appendix C.3). Furthermore, participants in both roles were trained with computerized tools that made them familiar with their role in the experiment before the payoff-relevant interaction started. Participants in the role of firms had access to a tool in which they could enter any combination of their own price and two prices for their competitors and the tool gave them feedback on the resulting profits. Participants in the role of an authority interacted with a training tool, which confronted them with three archetypical constellations that they had to audit. After they had given their judgment, participants received feedback about the expert's decision and an explanation for the correct answers. The experiment only starts once everyone had finished their use of the respective training tool.

\section{Research questions and hypotheses}

In this section, we introduce the theoretical background and our research questions before we develop a corresponding set of testable hypotheses for our experimental design. The first two hypotheses relate to the main measures for the success of a leniency rule, which are its impact on cartelization and prices. Thereafter, we turn to the use of the selfreport option and to the way firms communicate with each other, respectively. Both are important to understand how a leniency rule affects firm behavior. In Appendix A, we develop a theoretical framework that captures the main features of our experimental design and use this framework to derive hypotheses on treatment differences in cartel formation. We verify the theoretical predictions by numerically computing expected payoffs from our specific experimental design under equilibrium strategies. The design, the hypotheses, and the way we would test these were preregistered on OSF.

First, we want to better understand how a leniency rule affects the formation and stability of cartels because these are important criteria for the success of the leniency rule. In our model, we determine the discounted present value from colluding and deviating to compute the critical discount factor for collusion to be stable. The treatment difference arises because deviations in LENIENCY are optimally combined with self-reports (as fines are waived for the reporting firm) whereas they are not in FINE (as the reporting firm is also fined). In this setup, deviating is less profitable in Fine than in LENIENCY: in Fine, a cartel simply ends with a deviation, but it is not immediately fined because no firm has an incentive to self-report. If a random control takes places in later rounds after the deviation, the cartel members - including the deviator - may still be fined for previously being a member in the cartel. In LENIENCY, the cartel also ends, but the self-report of 
the deviator causes immediate fines for the other firms and, therefore, there is no risk of future fines for the deviator any more.

As a result of the above argumentation, the incentive compatibility constraint for the perfectly collusive outcome is tighter in LENIENCY than in FINE. The critical discount factor is higher in the leniency setting than without a leniency rule. This means that collusion can be sustained as an equilibrium for a larger range of discount factors, and supposedly is more stable, without a leniency rule than with one. Additionally, the leniency rule may also behaviorally undermine trust among (former) cartel members, which would strengthen this treatment difference. Thus, the incentive to step away from a cartel is always higher in LENIENCY than in FINE. For the same reasons, the leniency rule may also hinder the (re-)establishment of a cartel in LENIENCY compared to FinE.

Therefore, we expect that there is less cartelization in LENIENCY than in Fine (Hypothesis 1a). We also expect that cartels that were formed are more likely to endogenously break down (Hypothesis 1b), and are less likely to reform (Hypothesis 1c) in the presence of a leniency rule than without one.

Hypothesis 1a. The extent of cartelization is higher in Fine than in LENIENCY.

Hypothesis 1b. Cartels are less stable in LENIENCY than in Fine.

Hypothesis 1c. Cartels are reformed later when they have been convicted with the use of the leniency rule than without.

Second, we address the overarching question how a leniency rule affects the market price, which is an important outcome for policy makers. We start by asking how a leniency rule affects average market prices, i.e., not distinguishing between cartel and competitive phases. As we hypothesize that there will be less cartelization in LENIENCY than in Fine (see above) and cartels are characterized by supra-competitive prices, we expect that the leniency rule decreases average market prices (Hypothesis 2a). Further, we expect that prices during cartel phases are also lower in LENIENCY than in Fine (Hypothesis 2b) because the incentive compatibility constraint is tighter: cartels may try to coordinate on a lower price than the joint profit-maximizing price because this typically relaxes incentive compatibility due to a lower unilateral deviation profit. Again, this will decrease prices in cartel phases.

Hypothesis 2a. Average prices are lower in LENIENCY than in Fine.

Hypothesis $\mathbf{2 b}$. Average prices during cartel phases are lower in LENIENCY than in FINE.

We have no directed hypothesis regarding the treatment effect on prices in rounds that are not characterized by anticompetitive behavior according to the expert judgment; prices may be higher or lower with a leniency rule than without it. 
Next, we turn to the channels through which a leniency rule may affect firm behavior. Making cartels report themselves is the main lever that the leniency rule intends to activate. Thus, we ask how a leniency rule affects the frequency of reports of existing cartels. In the absence of a leniency rule, self-reports only reduce own payoffs. If a leniency rule is in place, however, fines are waived for the first self-reporting firm. Thus, self-reports are cheaper in LENIENCY than in Fine. At a higher level of reasoning, firms might also anticipate that others are more likely to self-report and, in turn, become more likely to self-report preemptively. Thus, we expect self-reports only in the LENIENCY treatment. In the experiment, there may also be few self-reports in the Fine treatment, but we would rather attribute them to errors or curiosity.

Hypothesis 3. Self-reports are used in LENIENCY but not in FINE. In particular, selfreports are used more often in LENIENCY than in FINE.

Finally, we want to understand how a leniency rule affects the way firms communicate with each other. Based on the reasoning behind hypothesis 3, we posit that participants understand the leniency rule as increasing the probability of controls. Due to the increased risk of being controlled and fined, we therefore expect that participants are more careful in their chat messages in LENIENCY than in FINE because they try to avoid punishment for explicit price coordination. This means that we expect them, e.g., to use the word 'price' (and its synonyms) less often than participants in FINE, and to write the number '9' or the word 'nine' (the joint profit maximizing price) as a description of the desired cartel price less often.

Hypothesis 4. Communication in LENIENCY is less explicit about prices than communication in FINE.

\section{Analysis and results}

In the following, we use our experimental data to test the specified hypotheses. We restrict ourselves to the data from the first 25 rounds of play as specified in the preregistration. We use this restriction because these rounds are played in all sessions, irrespective of the realizations of the random continuation mechanism, thus allowing for the cleanest treatment comparison. We first investigate cartelization and prices because these are the outcomes most relevant for competition authorities. We then investigate reporting behavior and communication as the channels that a leniency rule might affect.

Cartelization In order to examine how a leniency rule affects the formation of cartels, we compare cartelization across treatments. Our measure for the extent of cartelization 
is the ratio of rounds in which a cartel existed according to the judgment of the expert. ${ }^{15}$ As our primary measure, we compute the weighted ratio where the extent of the fine $(50 \%$ vs. 100\%), as decided by the expert, is used to weight the respective cartel rounds to account for the fact that anticompetitive behavior may be more or less severe. The average weighted cartelization is 0.34 rounds in LENIENCY $(N=27, S D=0.33$ rounds) and 0.32 rounds in Fine $(N=23, S D=0.25$ rounds). These two means are not significantly different at the 5\%-level based in a one-sided Wilcoxon-Mann-Whitney test $(p=0.45) .{ }^{16}$ The same holds if we use the unweighted ratio of rounds in which a cartel existed (mean $=0.39$ and $S D=0.34$ in LenienCy, mean $=0.46$ and $S D=0.29$ in Fine, $p=0.63$ ). Hence, our data does not support Hypothesis 1a that the extent of cartelization is larger in Fine than in LENIENCY.

We further analyze the distribution of cartelization in the two treatments. Figure 1 shows that the histograms of our cartelization measure are very similar in both treatments. Indeed, the distributions do not differ significantly in a Kolmogorov-Smirnov test. However, Figure 1 also suggests that there are more markets with very little or without any cartelization in LENIENCY than in FINE and more markets with an intermediate level of cartelization in FINE than in LENIENCY. In line with this observation, one-sided tests of proportions reveal significant differences in the proportion of markets with less than $10 \%$ of rounds with cartelization $(p=0.08)$ and in the proportion of markets with between $30-40 \%$ of the rounds being characterized by a cartel $(p=0.02)$. All other comparisons, however, do not yield significant differences, while the two significant differences might be due to chance.

We continue with the investigation of cartel duration. Our measure for the stability of cartels is the number of rounds that a cartel existed before break-down according to the unweighted expert judgment. As we are only interested in the endogenous break-down of cartels, we restrict attention to those cartels that do not end because of a control that is triggered by the exogenous detection probability.

The average duration of the first cartel formed in a group (if a cartel is formed at all) is 7.09 rounds in LENIENCY $(N=22, S D=8.34$ rounds $)$ and 8.33 rounds in Fine $(N=18$, $S D=6.31$ rounds). The decrease in duration in the presence of a leniency rule is not statistically significant at the $5 \%$-level based on a one-sided Wilcoxon-Mann-Whitney test $(p=0.12)$. Therefore, we do not find support for Hypothesis $1 \mathrm{~b}$.

Next, we look at cartel recidivism and compute how long it takes for a cartel to reform after it has broken down. We count the number of rounds that pass between the break-

\footnotetext{
${ }^{15}$ If we consider the binary judgment of whether or not a firm participated in a cartel, participants in the role of the competition authority come to the same judgment as the expert in $76 \%$ of the cases. If we consider the weighted judgment, which takes into account the severity of an infringement, and the duration of a cartel, the overlap between participant and expert judgment still amounts to $62 \%$.

${ }^{16}$ For all statistical tests, we treat each market as an independent observation.
} 


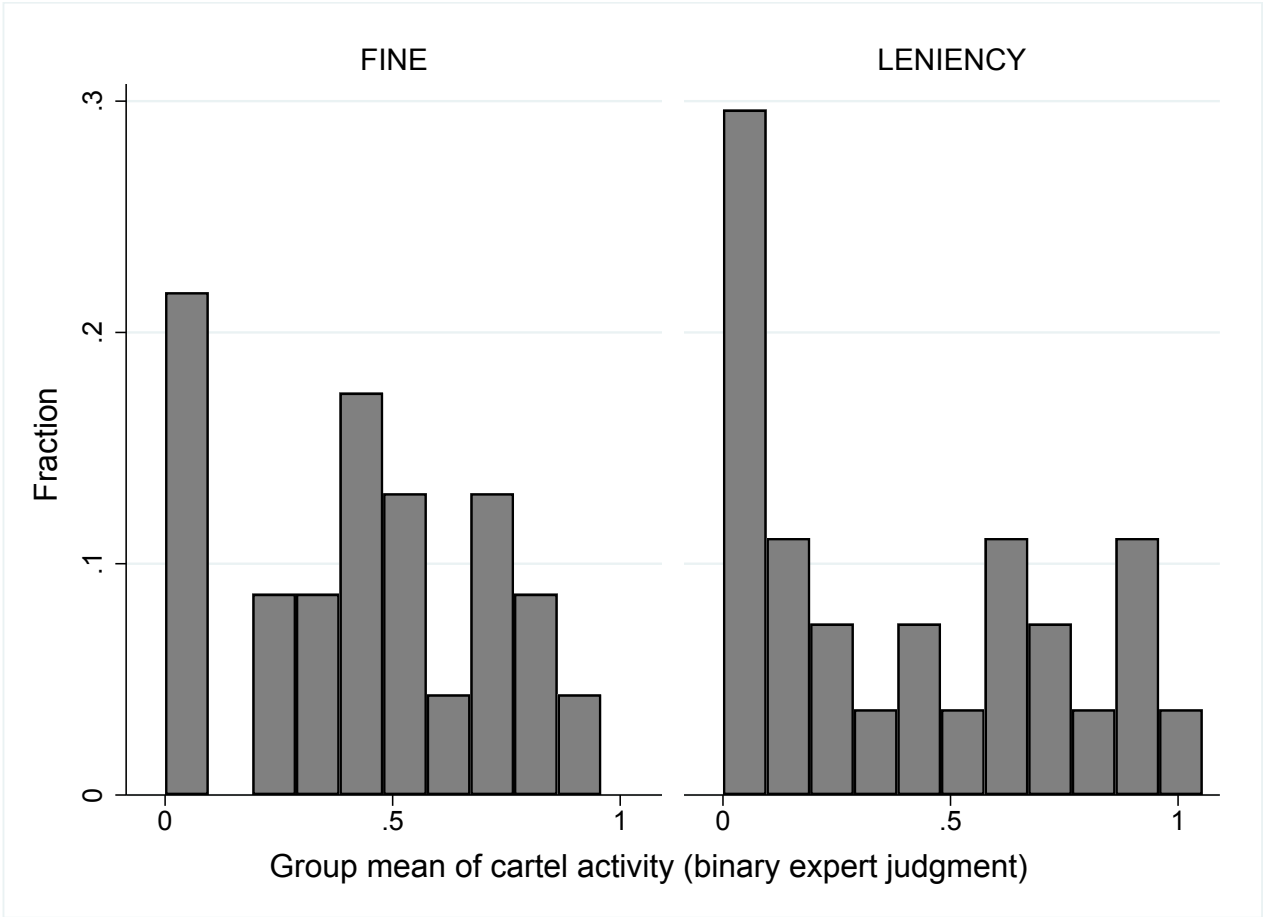

Figure 1: Histogram of cartelization by treatment.

down of the first cartel and the reestablishment of the second one, again according to the unweighted expert judgment. In groups where no second cartel has been formed until round 25, we assume that the cartel is reestablished in round 28, i.e., after the expected number of rounds is over. ${ }^{17}$

We find that cartels are reformed after 3.38 rounds in LENIENCY $(N=13, S D=$ 3.75 rounds) and after 3.33 rounds in Fine $(N=9, S D=2.87$ rounds), on average. Reformation does not occur later in LENIENCY than in FINE according to a one-tailed Wilcoxon-Mann-Whitney test with a $5 \%$ significance level $(p=0.5)$. Thus, our data do not support Hypothesis 1c.

Prices We first average prices per market over time (rounds 2 to 25) and then compare whether the average across groups of the average market price differs across treatments according to a one-tailed Wilcoxon-Mann-Whitney test. We find no statistically significant evidence $(p=0.49)$ that the average market price of 6.59 points in LENIENCY $(N=27$, $S D=1.45$ points $)$ is lower than that of 6.70 points in Fine $(N=23, S D=1.03$ points $)$. Thus, our data does not yield support for Hypothesis 2a.

\footnotetext{
${ }^{17}$ We use this assumption both for groups in which the cartel was not reestablished at all during the actual number of rounds played and for groups in which a cartel was reestablished after round 25 . We believe our assumption is a clean way to account for the fact that we commit to only using data from rounds 1 to 25 for our analysis.
} 


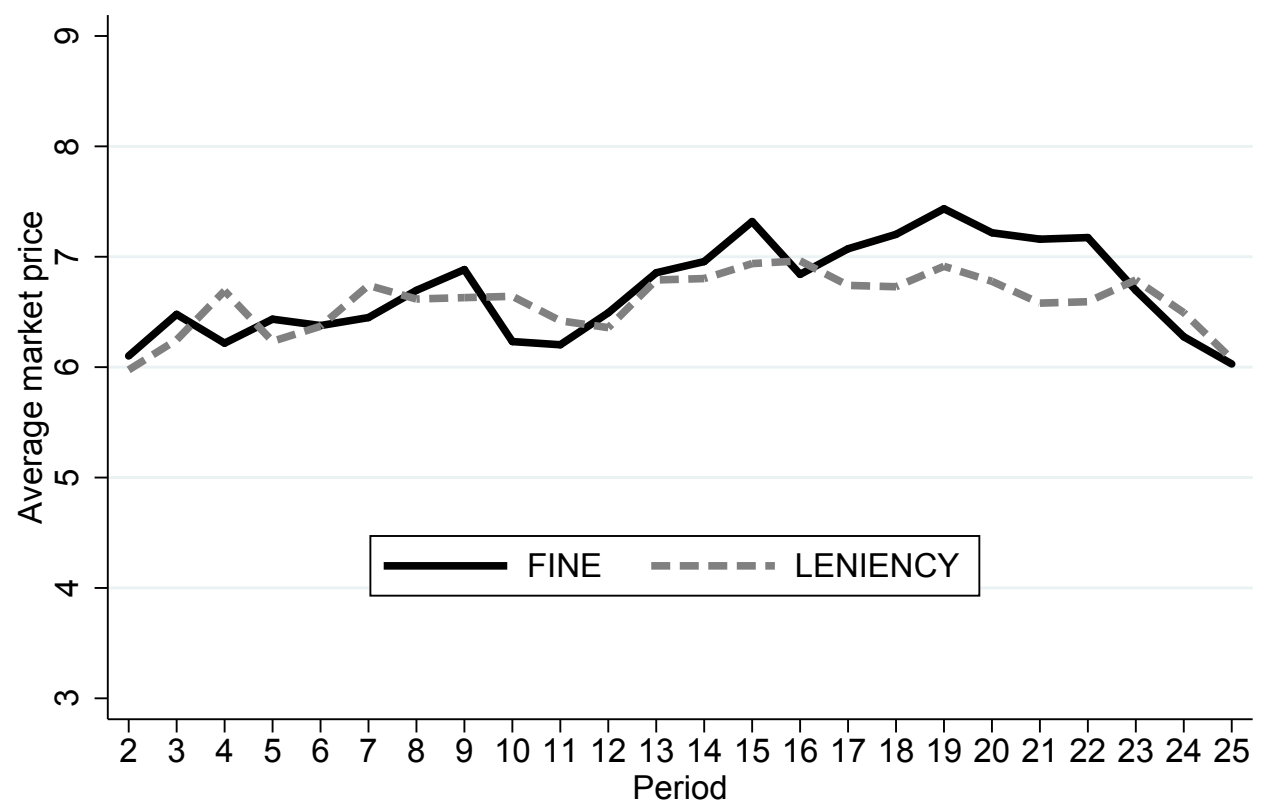

Figure 2: Average market prices over time by treatment.

We further explore the data and find no indication that the averages hide relevant differences. As shown in Figure 2, average prices in LENIENCY and Fine develop very similarly over time. ${ }^{18}$

We move on to compare average market prices between phases that are characterized by competitive or anticompetitive behavior according to the expert judgment, i.e., we average market prices over competitive and anticompetitive rounds at the group level, compute averages by treatment and competitive conduct, then compare the averages across treatments separately for competitive and anticompetitive conduct. Figure 3 illustrates that average prices during cartel phases are 7.88 points in Fine $(N=18, S D=0.96$ points) and 7.83 points in LENIENCY $(N=22, S D=1.16$ points $)$; these values do not differ significantly ( $p=0.44$ in a one-tailed Wilcoxon-Mann-Whitney test). Therefore, the data do not support Hypothesis $2 \mathrm{~b}$ that average prices during cartel phases are higher in Fine than in LENIENCY.

Figure 3 also illustrates that prices during phases that are not characterized by anticompetitive behavior are also very similar across treatments. Indeed, the average price of 5.68 points during competitive phases in FINE $(N=23, S D=1.21)$ is not significantly different from the average price of 5.74 during competitive phases in LENIENCY $(N=27$, $S D=1.07)$.

However, there is a significant difference between average prices during cartel phases and phases with competitive behavior in LENIENCY, FINE, and in both treatments pooled (the respective differences are all significant at the 1\%-level in a two-sided Wilcoxon-

\footnotetext{
${ }^{18}$ This impression is confirmed if we look at the average market price over time at the individual market level, see Appendix B for details.
} 


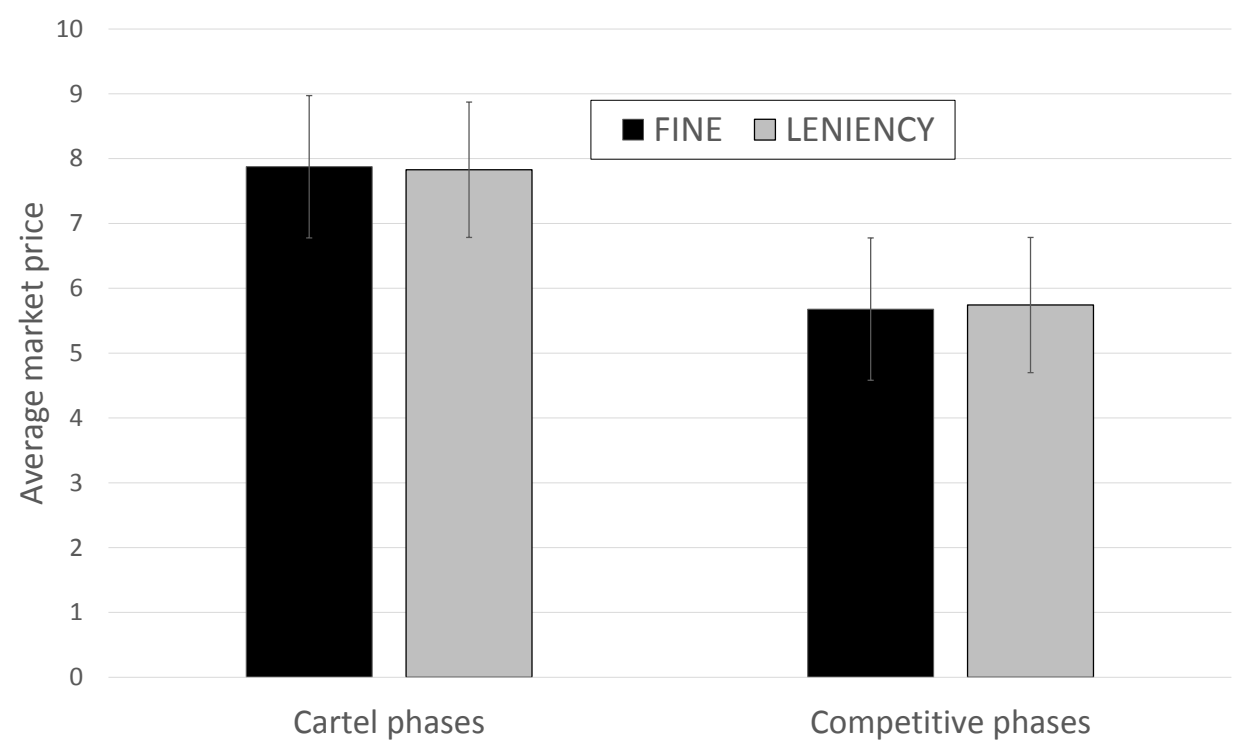

Figure 3: Average market prices by competitive conduct and treatment.

Mann-Whitney test). This result indicates that participants successfully form cartels by choosing higher prices during cartel phases in contrast to rounds in which no cartel is active independent of the existence of a leniency rule.

Self-Reporting On average, self-reporting occurred on average in 0.93 rounds in LENIENCY $(N=27, S D=1.33)$ and in 0.52 rounds in Fine $(N=23, S D=0.73)$ and therefore very rarely. The ratio of number of reports in a group to the number of cartels in the respective group is on average 0.77 in LENIENCY $(N=22, S D=1.18)$ and 0.39 in Fine $(N=15, S D=0.78) .{ }^{19}$ Tobit regressions reveal that these ratios are not statistically different from zero in either treatment $(p>0.8)$. This suggests that self-reporting across the two treatments is very similar. Accordingly, a one-sided Wilcoxon-MannWhitney test does not find a significant difference between the average ratio of rounds with reports to cartel rounds between LENIENCY and FINE at a significance level of 5\% $(p=0.27)$. Thus, we conclude that self-reports are not more frequent in the presence of a leniency rule and that our data yields no support for Hypothesis 3.

We further explore the data by looking at the individual cartels. We restrict attention to only the first cartel founded in each group to avoid dynamic effects from past reporting. Out of 18 first cartels in FINE one cartel is reported, whereas out of 22 cartels in LENIENCY five cartels are reported to the authority. The difference fails to reach significance in a onetailed test of equal proportions at the 5\%-level. Thus, even a more exploratory analysis of the data does not provide evidence supporting Hypothesis 3, which states that the leniency rule induces participants to self-report more often.

\footnotetext{
${ }^{19} \mathrm{We}$ drop groups in which no cartel round was observed. If we set those to zero, the average ratio is 0.62 in LENIENCY and 0.26 in Fine, i.e., differences become even smaller.
} 
Communication To investigate communication, we follow two separate approaches. First, we classify communication manually into explicit attempts to coordinate and then (a) count periods in which communication has or has not occurred and (b) count periods with explicit communication. We then compare the amount of (explicit) communication across treatments by first averaging group-level communication over time. On average, we find slightly more periods with communication in LENIENCY than in FINE, with groups communicating on average in $71 \%$ of rounds in FINE $(N=23, S D=0.31)$ and in $83 \%$ of the rounds in LENIENCY $(N=27, S D=0.23)$. This difference points in the opposite direction as we predicted, even though the difference is not statistically significant in a two-sided Wilcoxon-Mann-Whitney test $(p=0.22)$. Next, we investigate whether groups communicate less explicitly in the presence of a leniency rule. We find that groups in Fine communicate explicitly in $20 \%$ of the rounds $(N=23, S D=0.21)$, whereas those in LENIENCY do so in $22 \%$ of the rounds $(N=27, S D=0.20)$ on average. These averages are not statistically different in a two-sided Wilcoxon-Mann-Whitney test $(p=0.56)$. Thus, we find no support for Hypothesis 4.

Second, we compare the content of the chats after having followed a systematic natural language processing procedure, which aims to represent the chat data by tokens that are most likely to confer the content of text (Manning and Schütze, 1999; Gentzkow et al., 2019; Penczynski, 2019). Tokens are strings that are extracted out of the text such as words. We define each group chat as a document so that all group chats together constitute the corpus on which the procedure operates. We correct spelling mistakes in the chat, clean the text by removing stop words, and reduce all words to their stem such that, e.g., 'preference' and 'prefers' both become 'prefer'. ${ }^{20}$

Consistent with the null effects in terms of economic variables, we find that communication in both treatments is surprisingly similar. Figure 4 shows word clouds and plots the 15 most frequent tokens in the chat protocols by treatment after natural language processing. ${ }^{21}$ It is apparent that participants in both treatments talk about very similar content because the word clouds and the list of most frequent words overlap almost entirely. Overall, 14 out of the 15 most frequents tokens are identical. Interestingly, 'firm' (=firma) and the corresponding name '1', '2' and '3' are present in both figures. Closer inspection of figure 4 shows that only the 15 th token varies: 'competition authority'

\footnotetext{
${ }^{20}$ We use the $R$ package $t m$ published by Feinerer et al. (2008) to process the chat data. We use the list of stropwords, which are tokens that appear frequently in all texts and are unlikely to confer meaningful content such as 'the' or 'at', provided by Feinerer et al. (2008) and append tokens typical for chat messages in German such as 'wat' meaning 'what' in Berlin and Brandenburg. We use the $R$ package SnowballC published by Bouchet-Valat (2019) to stem words.

${ }^{21}$ Subjects write 'yes' (=ja), 'okay' and 'no' (=nein) very often, they talk about firms (=firma) and the number of firms $(1,2,3)$, they mention rounds of play (=rund), the 'competition authority' (=kartellamt), a price of nine and discuss how to improve outcomes typing 'always' (=imm), 'get' (=geht), more $(=$ mehr) as well as 'already' or 'nice' (=scho(ö)n), 'time' (=mal) and 'good' (=gut). Note, translating the depicted tokens outside their context and after stemming is problematic.
} 


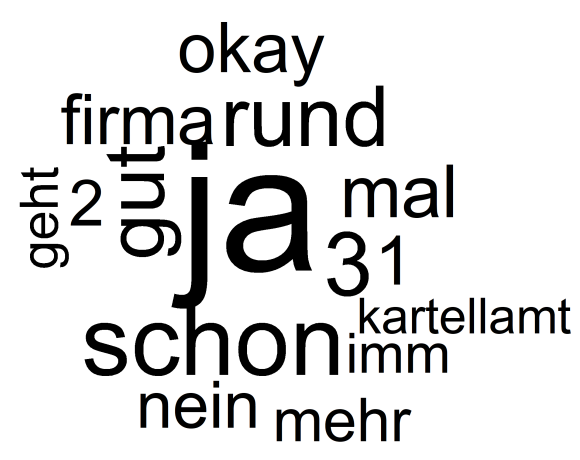

(a) Wordcloud in Fine

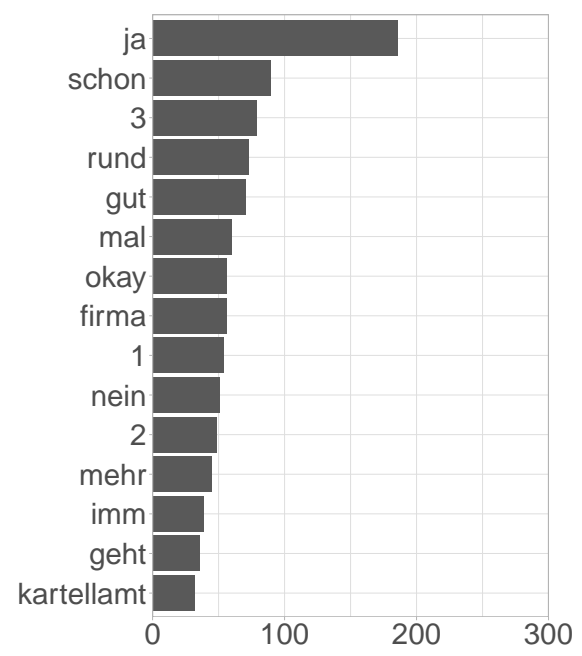

(c) Most frequent tokens in Fine

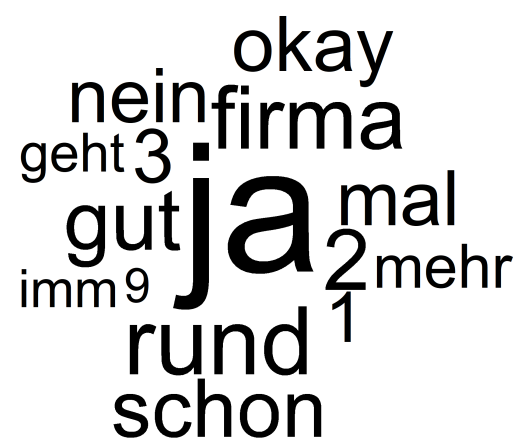

(b) Wordcloud in LENIENCY

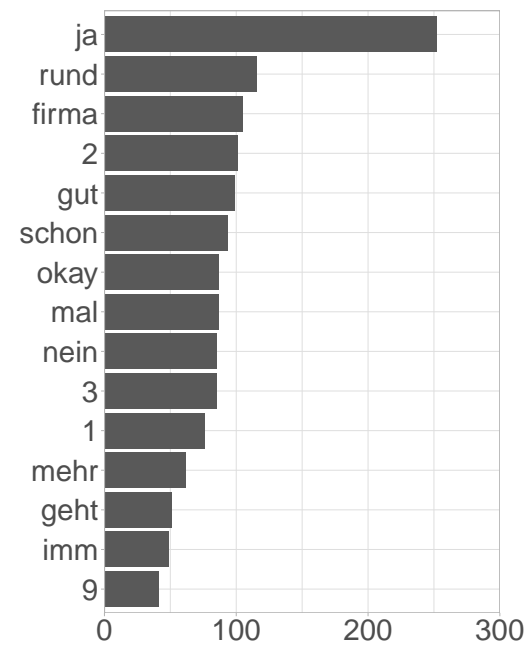

(d) Most frequent tokens in LENIENCY

Figure 4: Descriptive analysis of communication data.

(=kartellamt) in figure 4c and '9' in figure 4d. This is somewhat intuitive, as we classified slightly more communication as being explicit in LENIENCY as in FINE, although the difference is not significant. Thus, this rather proves our classification of text messages. To conclude, also at this more disaggregated level of analysis, we find no evidence for the leniency rule affecting the way firms communicate with each other significantly.

\section{Discussion}

Previous experimental studies found that a leniency rule is an effective instrument to hinder cartel formation. ${ }^{22}$ Our study did not replicate these results. We attribute the

\footnotetext{
${ }^{22} \mathrm{An}$ exception is the study of Dijkstra et al. (2018).
} 
difference to an important design innovation that allows for distinguishing between communication and cartel formation whereas these were equated in previous studies.

In previous experimental studies on the leniency rule, firms vote in a first stage whether to communicate with each other. If all firms in a market agree to communicate, this decision counts as a cartel being formed and participants know this when they decide about communication. Importantly, having voted for communication counts as a cartel regardless of whether the firms succeed in coordinating their prices or not. Thus, the decision to communicate is equivalent to the decision to form a cartel.

In contrast, our experimental design allows for innocuous communication and the communication channel is open in all markets. In our setup, firms are only considered to form a cartel if they indeed use communication to coordinate their prices. To allow for this differentiation of communication, our design includes a participant in the role of the competition authority who judges the content of communication and price setting jointly when determining fines for cartels. This design change may explain why the leniency rule was ineffective in our study for the following two reasons.

First, communication - even it does not directly address price coordination - can reduce uncertainty and enhance trust (see Odenkirchen, 2018, and the therein cited literature) so that cartels are ceteris paribus more likely to be formed and more stable. This cartel stabilizing effect of improved trust through communication may counteract the intended effect of the leniency rule and, thus, reduce any potential treatment difference. The fact that we observe far higher prices, fewer deviations, and fewer self-reports than, e.g., Bigoni et al. (2012) in a similar design ${ }^{23}$ is consistent with the interpretation that uncertainty was smaller and trust was larger in our setup than in previous studies.

Second, the voting stage strongly facilitated the formation of cartels. Forming a cartel by clicking a button on the computer screen is presumably far easier than doing so by coordinating a specific joint pricing behavior via free-form communication. Furthermore, the unanimity rule may reduce the perceived immorality of cartel formation due to a diffusion of responsibility. Accordingly, these studies found a lot of cartel formation. Among these, there were likely cartels that did not achieve profitable price coordination and also those that were inherently unstable because there was little room for the evolution of trust due to the absence of free-form communication. Thus, since there were many cartels, many reasons to self-report, and supposedly low levels of trust, a leniency rule, which aims at eroding trust among the firms, found an ideal playing field to unfold its effect in previous experimental studies.

\footnotetext{
${ }^{23}$ While average prices in our experiment are 6.7 in FINE and 6.6 in LENIENCY, Bigoni et al. (2012) report average price levels of 5.3 in FINE and 4.8 in LENIENCY, while using very similar payoff functions with prices also being restricted to the same range between 0 and 12 . The difference is particularly striking when taking into account that they had markets with two firms, which should have facilitated coordination in comparison to our setup with three firms per market.
} 


\section{Conclusion}

In this study, we revisit the effect of a leniency rule on cartelization. The main innovative element of our experiment is that we introduce a competition authority as an active player into the setup, in addition to participants in the role of firms. In comparison to previous studies, we thereby replace the binary and unanimous decision whether to form a cartel or not with a free-form communication possibility that precedes the price-setting stage. This free-form chat allows firms to communicate without explicitly forming a cartel. We obtain a reliable measure of cartelization in the form of the independent judgment of an expert in competition law.

We find that a leniency rule affects neither cartelization nor pricing behavior in this experimental design. This finding is in stark contrast to results from previous experimental studies. We argue that previous studies likely overestimate the size of the effect of a leniency rule on cartel formation because their setup created an environment that makes it particularly easy for the leniency rule to create distrust among the firms, thus reducing cartelization because a) the decision to communicate was set equivalent to the decision to form a cartel and b) communication was allowed only in a highly structured form. An exception in the previous literature is the study by Dijkstra et al. (2018) that allowed for free-form communication and also found the leniency rule to be largely ineffective. Due to the voting on communication/cartel formation, their setup is still likely to yield biased results on the extent of cartelization and the content of communication. This is evident from their observation that (some) firms agree to tacitly collude after detection and the corresponding finding of price hysteresis after cartel detection. According to judicial practice, this would be a continued cartel and should be fined but is not in their experimental study.

Based on our data and a careful consideration of the previous findings in light of the respective designs, we conclude that a leniency policy may not be very effective in generating distrust and destabilizing cartels by encouraging more self-reports. Empirically, this is consistent with the findings of Ormosi (2014), who estimates an upper bound of 20 percent of all existing cartels being detected. We conclude that reported and sanctioned cartels are likely only the "tip of the iceberg" and that it may be welfare-improving to endow competition authorities (that currently invest a large share of their resources into sanctioning reported cases) ${ }^{24}$ with sufficiently large budgets and investigative rights to allow more investigations to take place, even if no self-report is received.

In addition to our findings on the effect of a leniency rule on cartelization, the way in which we implemented the active authority in the experiment offers a methodological contribution in itself. This innovation allows researchers to solve practical problems in

\footnotetext{
${ }^{24}$ For example, the German competition authority reports that more than 50 percent of their cartel cases are opened after a self-report by one of the firms, see Bundeskartellamt (2016).
} 
related experimental studies such as the judgment whether a cartel has actually re-formed after being fined. Thus, this feature bears potential for increasing the external validity of experimental studies, which could also be useful for the study of other research questions related to price setting behavior.

\section{References}

Apesteguia, J., M. Dufwenberg, and R. Selten (2007). Blowing the whistle. Economic Theory 31(1), 143-166.

Bigoni, M., S.-O. Fridolfsson, C. Le Coq, and G. Spagnolo (2012). Fines, leniency, and rewards in antitrust. The RAND Journal of Economics 43(2), 368-390.

Bigoni, M., S.-O. Fridolfsson, C. Le Coq, and G. Spagnolo (2015). Trust, leniency, and deterrence. The Journal of Law, Economics, and Organization 31(4), 663-689.

Blonski, M., P. Ockenfels, and G. Spagnolo (2011). Equilibrium selection in the repeated prisoner's dilemma: Axiomatic approach and experimental evidence. American Economic Journal: Microeconomics 3(3), 164-192.

Bodnar, O., M. Fremerey, H.-T. Normann, and J. Schad (2019). The effects of private damage claims on cartel stability: Experimental evidence. Number 315. DICE Discussion Paper.

Bouchet-Valat, M. (2019). SnowballC: Snowball stemmers based on the C libstemmer utf-8 library. $R$ package version 0.6.0.

Breitmoser, Y. (2015). Cooperation, but no reciprocity: Individual strategies in the repeated prisoner's dilemma. American Economic Review 105 (9), 2882-2910.

Brenner, S. (2009). An empirical study of the european corporate leniency program. International Journal of Industrial Organization 27(6), 639-645.

Bundeskartellamt (2016). Erfolgreiche Kartellverfolgung. Nutzen für Wirtschaft und Verbraucher. https://www. bundeskartellamt.de/SharedDocs/Publikation/ DE/Broschueren/Informationsbrosch\%C3\%BCre $\% 20-\% 20$ Erfolgreiche $\%$ 20Kartellverfolgung.pdf?_-_blob=publicationFile\&v=12 Accessed: 2019-0902 .

Clemens, G. and H. A. Rau (2019). Do discriminatory leniency policies fight hard-core cartels? Journal of Economics \& Management Strategy 28(2), 336-354.

Dal Bó, P. and G. R. Fréchette (2018). On the determinants of cooperation in infinitely repeated games: A survey. Journal of Economic Literature 56(1), 60-114. 
Dijkstra, P. T., M. A. Haan, and L. Schoonbeek (2018). Leniency programs and the design of antitrust: Experimental evidence with free-form communication. University of Groningen. Mimeo.

Feinerer, I., K. Hornik, and D. Meyer (2008). Text mining infrastructure in R. Journal of Statistical Software 25(5), 1-54.

Fonseca, M. A. and H.-T. Normann (2012). Explicit vs. tacit collusion-The impact of communication in oligopoly experiments. European Economic Review 56(8), 17591772.

Fonseca, M. A. and H.-T. Normann (2014). Endogenous cartel formation: Experimental evidence. Economics Letters 125(2), 223-225.

Gentzkow, M., B. Kelly, and M. Taddy (2019). Text as data. Journal of Economic Literature 57(3), 535-574.

Gomez-Martinez, F., S. Onderstal, and J. Sonnemans (2016). Firm-specific information and explicit collusion in experimental oligopolies. European Economic Review 82, 132141.

Harrington Jr, J. E. (2004). Post-cartel pricing during litigation. The Journal of Industrial Economics 52(4), 517-533.

Harrington Jr, J. E. (2008). Optimal corporate leniency programs. The Journal of Industrial Economics 56(2), 215-246.

Harrington Jr, J. E. (2017). A proposal for a structural remedy for illegal collusion. Antitrust Law Journal, Forthcoming.

Harrington Jr, J. E. and M.-H. Chang (2015). When can we expect a corporate leniency program to result in fewer cartels? The Journal of Law and Economics 58(2), 417-449.

Harrington Jr, J. E., R. H. Gonzalez, and P. Kujal (2016). The relative efficacy of price announcements and express communication for collusion: Experimental findings. Journal of Economic Behavior $\&$ Organization 128, 251-264.

Hesch, M. (2012). The effects of ringleader discrimination on cartel stability and deterrence-experimental insights. Journal of Advanced Research in Law ES Economics (De Gruyter Open) 3(5), 26-42.

Hinloopen, J. and S. Onderstal (2014). Going once, going twice, reported! Cartel activity and the effectiveness of antitrust policies in experimental auctions. European Economic Review 70, 317-336. 
Hinloopen, J. and A. R. Soetevent (2008). Laboratory evidence on the effectiveness of corporate leniency programs. The RAND Journal of Economics 39(2), 607-616.

Manning, C. D. and H. Schütze (1999). Foundations of Statistical Natural Language Processing. The MIT Press.

Marvão, C. M. P. and G. Spagnolo (2014). What do we know about the effectiveness of leniency policies? A survey of the empirical and experimental evidence. Number 28. SITE Working Paper.

Marvão, C. M. P. and G. Spagnolo (2018). Cartels and leniency: Taking stock of what we learnt. In L. C. Corchón and M. A. Marini (Eds.), Handbook of Game Theory and Industrial Organization, Volume 2, pp. 57-90. Edward Elgar Publishing.

Miller, N. H. (2009). Strategic leniency and cartel enforcement. American Economic Review 99(3), 750-768.

Motta, M. and M. Polo (2003). Leniency programs and cartel prosecution. International Journal of Industrial Organization $21(3), 347-379$.

Odenkirchen, J. (2018). Pricing behavior in partial cartels. Number 299. DICE Discussion Paper.

Organisation for Economic Co-operation and Development (2002). Fighting hard-core cartels: Harm, effective sanctions and leniency programmes. https://www.oecd.org/ competition/cartels/1841891.pdf Accessed: 2019-06-06.

Ormosi, P. L. (2014). A tip of the iceberg? The probability of catching cartels. Journal of Applied Econometrics 29(4), 549-566.

Penczynski, S. P. (2019). Using machine learning for communication classification. Experimental Economics, 1-28.

Spagnolo, G. (2004). Divide et impera: Optimal leniency programs. Number 4840. CEPR Discussion Paper.

Spagnolo, G. (2008). Leniency and whistleblowers in antitrust. In P. Buccirossi (Ed.), Handbook of Antitrust Economics, pp. 259-303. The MIT Press.

Wandschneider, F. (2014). Four essays on optimal antitrust enforcement. Ph. D. thesis, University of East Anglia. 


\section{Appendix}

\section{A Theoretical background}

In this section, we derive the critical discount factors for a repeated game that provides the background for our experimental design.

In the experiment, participants interact in groups of four, consisting of a market of three firms and one competition authority. The interaction between the firms is characterized by Bertrand competition with differentiated products. The same firms play the following stage game repeatedly.

Stage game: We let the quantity sold by each firm i given its own price $p_{i}$ and the prices of its two competitors $j$ and $k, p_{j}$ and $p_{k}$, be given by:

$$
Q_{i}\left[p_{i}, p_{j}, p_{k}\right]=\frac{a}{1+\gamma}-\frac{1}{1-\gamma^{2}} p_{i}+\frac{\gamma}{1-\gamma^{2}} \frac{p_{j}+p_{k}}{2}
$$

Per period profit for each firm is computed as $\left(p_{i}-c\right) Q_{i}$ where $c$ is the unit cost of production that we normalize to zero for simplicity. Then firm $i$ 's profit as a function of its own and the competitors' prices is given by:

$$
\Pi_{i}\left[p_{i}, p_{j}, p_{k}\right]=\frac{a}{1+\gamma} p_{i}-\frac{1}{1-\gamma^{2}} p_{i}^{2}+\frac{\gamma}{1-\gamma^{2}} \frac{p_{i}\left(p_{j}+p_{k}\right)}{2}
$$

We use the parameterization $a=35, \gamma=\frac{4}{5}$. This yields $p=6$ as the Nash equilibrium price of the stage game with a corresponding per firm profit of $\Pi=100$. The symmetric joint profit maximizing price is $p=18$ and yields a per firm profit of 180 . Given collusive behavior of the other two firms, the optimal unilateral undercutting price is $p=10.8$ which we round down to 10 for the experiment. Deviating to a price of 10 yields a deviation profit of 322 (rounded to the next integer). The other two firms that have been cheated upon make a profit of only 20 in the respective period if they both continue to charge the collusive price of 18 .

For the implementation in the laboratory experiment, we relabel all prices by dividing them by 2 and restrict the price setting range to the integers from 0 to 12 (corresponding to all even valued prices from 0 to 24 in the above given formulae, as in Bigoni et al., 2012). All prices above 24 are at least weakly dominated by those prices in the restricted range. Thus, this only helps to simplify the experiment.

Controls and fines: A cartel can be detected and fined during its existence and after its end. In each round a control of the competition authority is launched with an exogenous 
probability of $10 \%$ or because a firm self-reported its cartel. If a control is launched an existing or past cartel is detected and fined with certainty.

A cartel member is fined based on its cumulative profits during the participation in a collusive agreement as judged by the competition authority. However, past profits can only to some extent be reduced by a fine. If a control takes place in period t, the size of the fine in percentage of profits is computed according to the accumulated profits since the last control has taken place, weighted by the cartel duration. This percentage is deduced from the profits in the round, in which the control has taken place, and at most four preceding rounds that have lower impact the further past they are. Collusive profits from period t are reduced by $100 \%$ of the fine size, profits from period t -1 by $80 \%$ of the fine, profits from period t- 2 to $60 \%$, profits from period t- 3 to $40 \%$, and profits from a collusive agreement in period t- 4 to $20 \%$. Profits from a collusive agreement in period t- 5 or earlier are only relevant for the computation of a potential fine (in percent of profit), but the fine is not applied to these profits. This ensures that fine sizes in our setup correspond approximately to the magnitude of real cartel cases.

Feedback, fines, punishment of deviations: We assume that a deviation from a cartel is detected by the other firms immediately due to the complete feedback about each firm's price setting. Expected fines are increasing during the first five rounds of each cartel phase. For the computations that relate to perfectly collusive behavior, we assume that the fine is perceived as a fixed fine with the size that can be expected in our setup when the collusive agreement is perfect, i.e., all members always set the joint profit-maximizing price which results in per-period-per-firm profits of $\Pi^{c}=180$. Then, using the linear depreciation of fine-relevant profits as introduced above, the expected fine in an infinitely repeated game when colluding perfectly equals $F=540$. We further assume that deviations as well as reports will be punished by playing Nash forever after.

Repetition: Suppose that time is discrete and that the stage game is repeated infinitely often with the participants discounting future payoffs with a discount factor $\delta$. For the analysis of the repeated game, we restrict attention to the following set of stage game payoffs: the payoff from the Nash equilibrium in the stage game, $\Pi^{n}=100$, the payoff from the joint-profit-maximizing price in the stage game (the collusive or cartel payoff), $\Pi^{c}=180$, the deviation payoff that is made from an optimal unilateral deviation from the collusive agreement, $\Pi^{d}=322$, and the payoff that is made by the remaining cartel members when one member deviates, $\Pi^{b}=20$. It holds that $\Pi^{b}<\Pi^{n}<\Pi^{c}<\Pi^{d}$.

We only consider settings with law enforcement and compare the games that ensue with and without a leniency rule that exempts the firm that first self-reports a cartel from paying any fine for past collusive behavior. 
Participation constraints: First, consider the participation constraint for collusion. This reads in both the leniency and the no-leniency setting as

$$
\frac{\Pi^{c}-\Pi^{n}}{1-\delta}>\frac{\alpha F}{1-\delta}
$$

With the parameters in the experiment, this is clearly fulfilled because $80>54$. Next, consider the incentive compatibility constraints of collusion.

Incentive compatibility without a leniency rule: Without a leniency rule, the value of the strategy "sticking to the collusive agreement", i.e., setting each period the joint-profit-maximizing price and doing so even if the cartel has been detected through the exogenous detection mechanism, is:

$$
V^{c}=\frac{\Pi^{c}+\alpha\left(\delta V^{c}-F\right)}{1-(1-\alpha) \delta}=\frac{\Pi^{c}+\alpha \delta V^{c}-\alpha F}{1-(1-\alpha) \delta}
$$

Solving for $V^{c}$ this yields

$$
V^{c}=\frac{\Pi^{c}-\alpha F}{1-\delta}
$$

We assume that as part of the strategy "sticking to the collusive agreement" cartel members continue to collude if their cartel has been detected due to a control that was triggered by the exogenous detection probability. This implies that their cartel continues to exist after such a control; and it also continues to face the exogenous risk of being detected and fined in every single period.

Consider now the possibility of deviating from the collusive agreement. Any such deviation is immediately observed by the cartel members (there is feedback on all prices set in a period, making it easy to observe the deviation). We assume that a deviation is punished by reverting to the Nash equilibrium of the stage game forever after. The value from deviating once and being punished is

$$
V^{d}=\Pi^{d}+\delta \frac{\Pi^{n}}{1-\delta}-\frac{\alpha F}{1-(1-\alpha) \delta}
$$

The third term results from the possibility of a cartel being detected and fined with exogenous probability also after it has broken down. As the cartel is assumed to never reform, the cartel can only be detected once after the deviation. 
The incentive compatibility constraint in a setting without leniency (our treatment named FINE) is therefore

$$
\frac{\Pi^{c}-\alpha F}{1-\delta}>\Pi^{d}+\delta \frac{\Pi^{n}}{1-\delta}-\frac{\alpha F}{1-(1-\alpha) \delta}
$$

From this constraint, we compute the critical discount factor which determines the range of discount factors for which, given all the other parameters in our experiment, collusion can be sustained as an equilibrium.

Solving the above constraint for $\delta$, we obtain a quadratic equation which has only one solution that lies in the interval $[0,1]$ and therefore has a unique admissible solution $\delta_{N}=0.682711$.

Incentive compatibility with a leniency rule: Consider now a setting with a leniency rule, i.e., the first firm that self-reports a collusive agreement is exempt from paying a fine. This implies that any deviation from the collusive agreement is coupled with a self-report in order to pre-empt the other firms that would report the cartel once they learn about the deviation. Thus, the value from defecting from the collusive agreement becomes:

$$
V^{d}=\Pi^{d}+\delta \frac{\Pi^{n}}{1-\delta}
$$

Reporting the cartel leads to an immediate fine to the other cartel members but not the self-reporting deviator. Moreover, the self-report implies that the cartel, which is assumed not to be reformed because of the Nash reversion punishment, does not face any detection risk in the future.

Thus, the incentive compatibility constraint in a setting with a leniency rule (named LENIENCY) is

$$
\frac{\Pi^{c}-\alpha F}{1-\delta}>\Pi^{d}+\delta \frac{\Pi^{n}}{1-\delta}
$$

From this constraint, we also compute the critical discount factor given all other parameters. Setting the above incentive constraint to bind and solving for $\delta$, we obtain the unique solution $\delta_{L}=0.883$.

Note that the critical discount factor of an infinitely repeated discounted game with punishment by Nash reversion exceeds $2 / 3$ in the cases with and without leniency. Collu- 
sion is therefore not an equilibrium of the continuation game starting in round 25, neither in Fine nor in LEnIENCY. According to a strict backward induction argument, collusion in the repeated game starting from the first round cannot be supported as a (subgameperfect) equilibrium in either treatment. When we, however, compute implicit discount factors for the still to be expected duration of the interaction in a given period, assuming that the uncertain end prevents unraveling of cooperation, we find that collusion can be supported throughout the first 25 rounds of play in both treatments. 


\section{B Additional results}

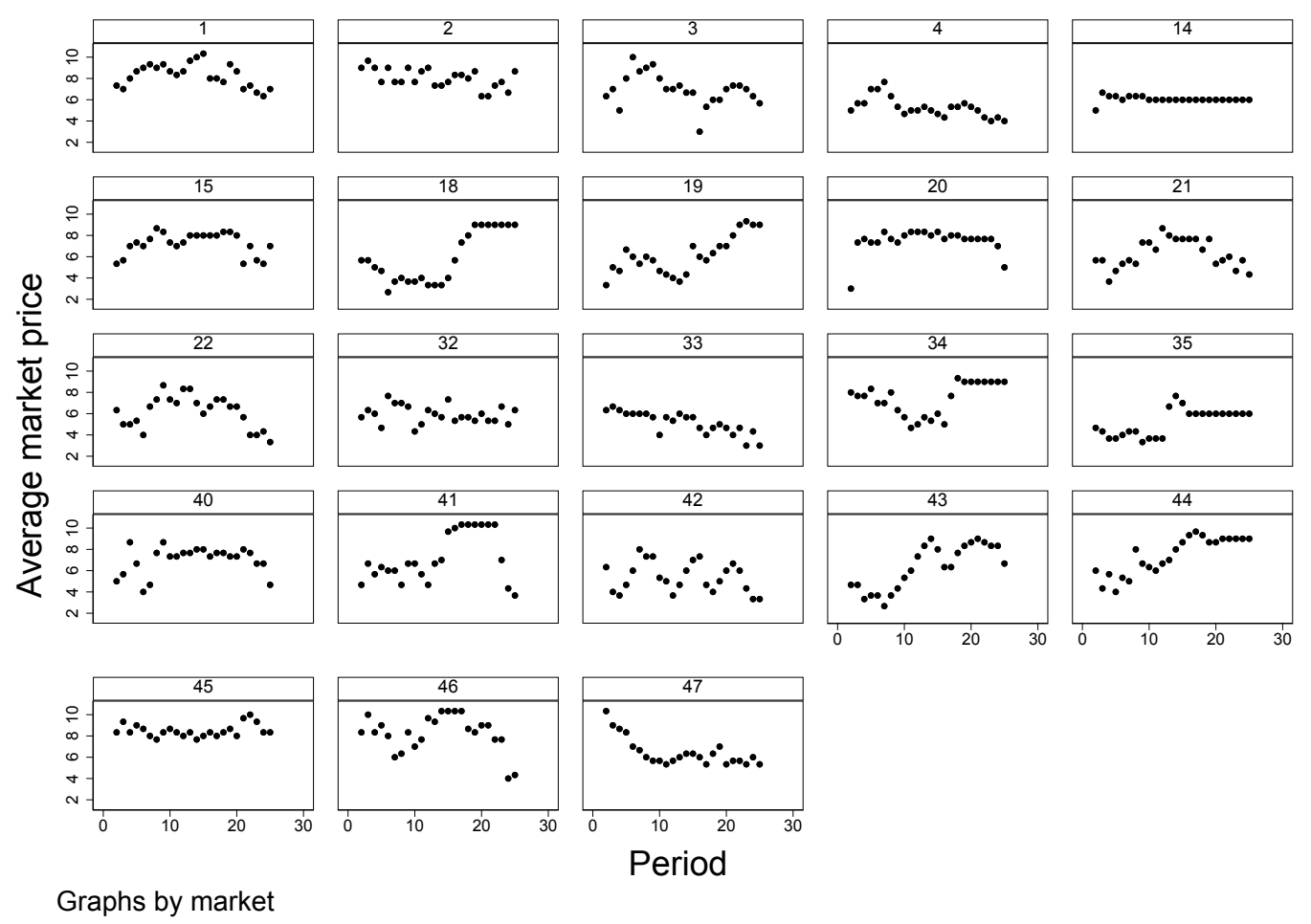

Figure 5: Prices by market (each group of three firms forms a market): FinE
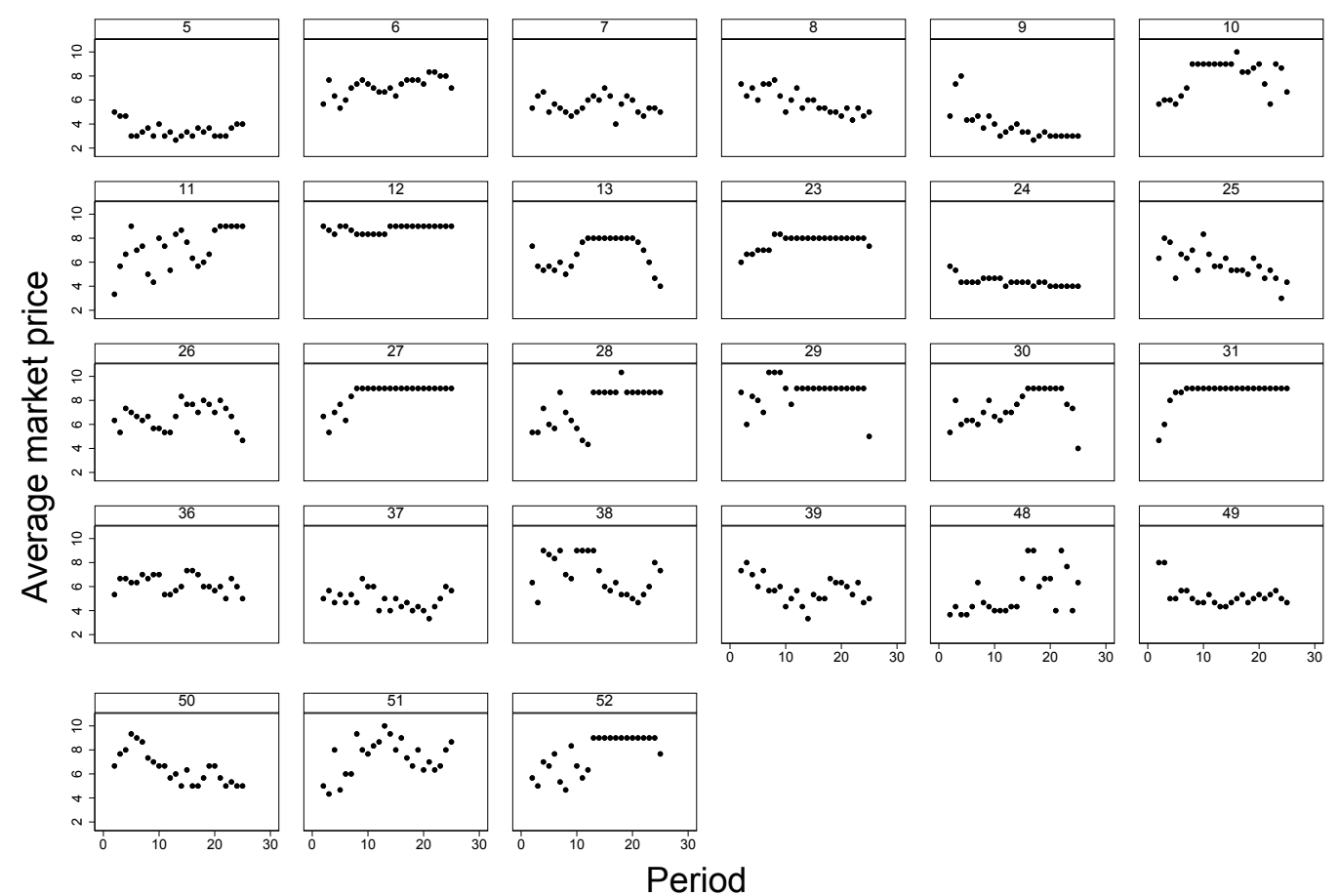

Graphs by market

Period

Figure 6: Prices by market (each group of three firms forms a market): LENIENCY 


\section{Instructions}

In the following, we present our instructions for firms in Section C.1 and for authorities in Section C.2. Please note, that text in italics only appears in instructions for the LENIENCY treatment.

\section{C.1 Instructions for Firms}

Today you are participating in a decision-making experiment. If you read the following instructions carefully, you can earn money. The amount of money you receive depends on your decisions and the decisions of other participants.

For the entire duration of the experiment it is prohibited to communicate with other participants. Therefore, we ask you not to talk to each other. Violation of this rule will result in exclusion from the experiment and payment.

If there is something you do not understand, please have another look at these instructions or give us a hand signal. We will then come to your seat and answer your question personally.

During the experiment, we do not talk of euros but of points. The number of points you earn during the experiment will be converted into euros as follows:

\section{Points $=1$ euro}

At the end of today's experiment, you will receive the points earned in the experiment converted into euros in cash plus 5 euros as basic endowment.

On the following pages we will explain the exact procedure of the experiment to you, starting with the general procedure. We will then familiarize you with the procedure on the screen. Then, you will have the opportunity to familiarize yourself on the computer screen with the calculation of profits in the experiment before the experiment begins.

\section{The Experiment}

At the start of the experiment, you will be matched randomly into a group with three other participants. During the experiment, you will make decisions within this group of four persons in total. The composition of your group remains the same throughout the entire experiment. Neither you nor the other participants will be informed about the 
identity of the participants in the group - neither during nor after the experiment.

The experiment consists of at least 25 rounds. You will receive more information on the number of rounds on page 5 of this document.

Every participant in your group represents either a firm or the competition authority. There are three firms (firm 1, 2 and 3) and one competition authority. In all rounds, you take the role of a firm. At the start of the experiment, you will be informed onscreen about which firm you are. You will be the same firm during the entire experiment.

The firms 1, 2 and 3 sell the same (fictional) good on the same market. Production of this good is costless for the firms. All firms decide simultaneously what price they want to charge for the good in a round. The price must be an integer between 0 and 12 . If a firm does not enter its own price and clicks the OK button within 30 seconds $(60$ seconds in the first round only), a price of 0 is automatically set for this firm.

Your profit depends on your own price and the average price of the other two firms. Your profit is larger the higher the prices of the other two firms are. Your own price has two effects on your own profit: If you increase your own price, the quantity you sell decreases, but at the same time your earnings per unit sold increases. Depending on which effect is larger, your profit increases or decreases. The table on the following page shows your profit, depending on your own price and the averages prices of the other two firms. (This table is the same for all three firms, read from their perspective.) 
Your profit, depending on the average price of the two other firms

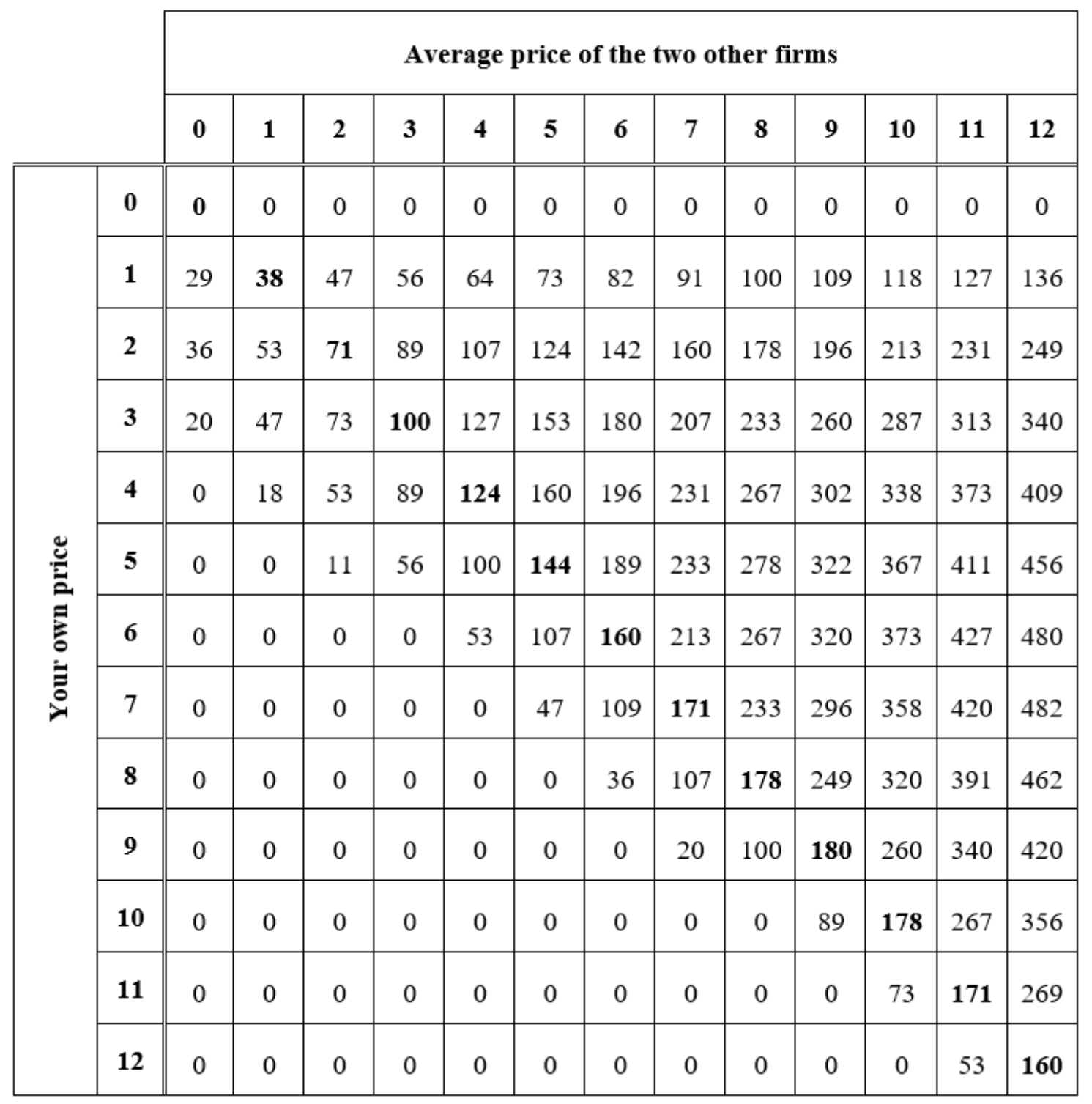


From the second round on, you have the option to communicate with the other firms via chat messages at the beginning of each round. The duration of a chat cannot exceed 60 seconds in one round. In this chat, you can write anything you want with the exception that you are not allowed to reveal hints on your identity.

$\S 1$ GWB of the Act against Restraints of Competition prohibits price agreements and the attempt of price agreements (for the exact wording, see the box).

$\S 1$ Prohibition of Agreements Restricting Competition

Agreements between undertakings, decisions by associations of undertakings and coordinated practices which have as their object or effect the prevention, restriction or distortion of competition are prohibited.

At the end of a round, the chat messages can be subject to an audit. In an audit, the competition authority judges whether the texts you and the other firms wrote in the chat are in accordance with $\S 1$ GWB. Such an audit can be initiated in two ways, by a random mechanism and by the firms:

- In each round, a random mechanism decides whether an audit takes place or not. This random mechanism is programmed so that an audit takes place with a probability of $10 \%$ (i.e. on average in 10 out of 100 cases).

- In addition, in each round the firms have the opportunity to initiate an audit themselves, both while setting their price and after they have learned the prices of the other firms. You can initiate an audit by clicking on a small white box at the bottom left of the screen. Initiating an audit cannot be undone. As soon as you click on the small white box, the box for that round disappears and an audit will definitely take place. The same applies to the other two firms in your group.

When an audit takes place, the competition authority has insight into all communication in the previous chats in your group as well as into the pricing since the first round. The competition authority imposes penalties on firms that have violated $\S 1$ GWB. It decides on the individual penalties for each of the three firms and for how long an agreement has been in place.

The penalty may be $0 \%, 50 \%$ or $100 \%$ of a firm's accumulated pecuniary profit during the agreement. $0 \%$ (no penalty) means that the firm has acted in accordance with $\S 1$ GWB, $100 \%$ means a clear, serious violation. $50 \%$ should be chosen for less serious violations. 
The pecuniary profit is measured according to your profit that you have earned and the duration of the agreement. However, if the agreement has been in place for more than five rounds, the penalty will only be applied to the profits of the last five rounds. Previous rounds are included in the calculation of the penalty, but will not be punished themselves.

The competition authority has three minutes to reach its decision.

The active initiation of an audit by a firm leads to the possibility that that firm is exempted from punishment. If only one firm has initiated the audit, that firm will automatically receive full amnesty. If two or three firms have initiated an audit, the penalty will only be waived for the firm that first initiated the audit.

After each round, the firms are informed about their own price, their profit and, if applicable, their penalty. In addition, each firm is informed about the prices set by the other two firms in the current round and, if applicable, their penalties. You will also be informed on whether a firm has initialized an audit by the competition authority and has thus received an exemption of its penalty.

From the 25th round on, a random mechanism decides in each round whether the experiment ends with the last round completed. With a probability of $33.3 \%$ (i.e. in an average of 1 out of 3 cases) the experiment ends with the last round completed. With a probability of $66.7 \%$ (i.e. in 2 out of 3 cases) another round takes place. In addition, it is ensured that the experiment does not last longer than 2 hours and 30 minutes.

After the last round, you will see an overview screen showing you how many points you have earned in total. You will receive all points converted into euros directly after the experiment.

If something is not clear to you, please give a clear hand signal. We will then come to your seat.

After the experiment we will ask you to fill out a short questionnaire on the computer. You will then receive your payment. 


\section{C.2 Instructions for Authorities}

Today you are participating in a decision-making experiment. If you read the following instructions carefully, you can earn money. The amount of money you receive depends on your decisions.

For the entire duration of the experiment it is prohibited to communicate with other participants. Therefore, we ask you not to talk to each other. Violation of this rule will result in exclusion from the experiment and payment.

If there is something you do not understand, please have another look at these instructions or give us a hand signal. We will then come to your seat and answer your question personally.

During the experiment, we do not talk of euros but of points. The number of points you earn during the experiment will be converted into euros as follows:

\section{Points $=1$ euro}

As an exception, this time you will not receive your payment for today's experiment in cash at the end of the experiment, but in about 2-3 weeks via bank transfer. You will receive more information on the bank transfer on page 6 of these instructions. In addition to your other earnings in this experiment, you will receive 10 euros in cash.

On the following pages we will explain the exact procedure of the experiment to you, starting with the general procedure. We will then familiarize you with the procedure on the screen. Then, you will have the opportunity to familiarize yourself on the computer screen with your task in the experiment before the experiment begins.

\section{The Experiment}

At the start of the experiment, you will be matched randomly into a group with three other participants. During the experiment, you will make decisions within this group of four persons in total. The composition of your group remains the same throughout the entire experiment. Neither you nor the other participants will be informed about the identity of the participants in the group - neither during nor after the experiment.

The experiment consists of at least 25 rounds. You will receive more information on the number of rounds on page 6 of this document. 
Every participant in your group represents either a firm or the competition authority. There are three firms (firm 1,2 and 3) and one competition authority. In all rounds, you take the role of the competition authority.

The firms 1, 2 and 3 sell the same (fictional) good on the same market. Production of this good is costless for the firms. All firms decide simultaneously what price they want to charge for the good in a round. The price must be an integer between 0 and 12 . If a firm does not enter its own price and clicks the OK button within 30 seconds, a price of 0 is automatically set for this firm.

The profit of a firm depends on its own price and the average price of the other two firms. The profit is larger the higher the prices of the other two firms are. The own price has two effects on the profit of a firm. If the own price increases, the quantity sold by this firm decreases, but at the same time the earnings per unit sold increases. Depending on which effect is larger, a firm's profit increases or decreases. The table on the following page shows the profit of a firm, depending on its own price and the averages prices of the other two firms. (This table is the same for all three firms.) 
A firm's profit, depending on the average price of the two other firms

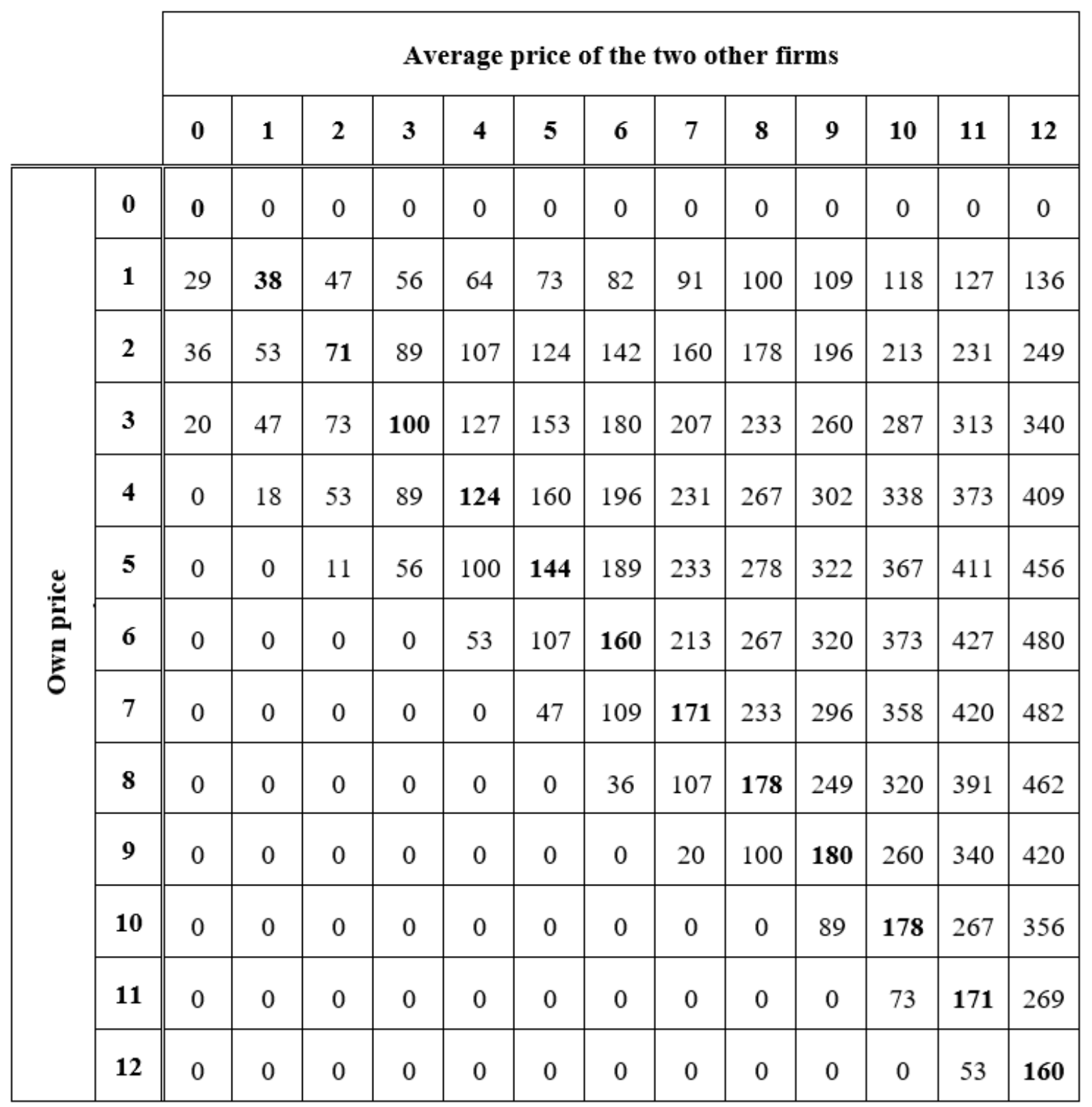


From the second round on, the firms have the option to communicate via chat messages. The duration of chat cannot exceed 60 seconds.

$\S 1$ GWB of the Act against Restraints of Competition prohibits price agreements and the attempt of price agreements (for the exact wording, see the box).

$\S 1$ Prohibition of Agreements Restricting Competition

Agreements between undertakings, decisions by associations of undertakings and coordinated practices which have as their object or effect the prevention, restriction or distortion of competition are prohibited.

At the end of a round, the chat messages can be subject to an audit. In an audit, you as the competition authority judge whether the texts the firms wrote in the chat are in accordance with $\S 1$ GWB. Such an audit can be initiated in two ways, by a random mechanism and by the firms:

- In each round, a random mechanism decides whether an audit takes place or not. This random mechanism is programmed so that an audit takes place with a probability of $10 \%$ (i.e. on average in 10 out of 100 cases).

- In addition, in each round the firms have the opportunity to initiate an audit themselves, both while setting their price and after they have learned the prices of the other firms. A firm can initiate an audit by clicking on a small box on the screen.

When an audit takes place, you will not be informed on how it was initiated. You have insight into all communication in the previous chats in your group as well as into the pricing since the first round. Your task is to impose penalties on firms that have violated $\S 1$ GWB. You decide on the individual penalties for each of the three firms and for how long an agreement has been in place. The duration is the number of all rounds since the last audit (or since the start of the experiment) in which, in your opinion, an agreement had a visible effect on the prices.

The penalty may be $0 \%, 50 \%$ or $100 \%$ of a firm's accumulated pecuniary profit during the agreement. $0 \%$ (no penalty) means that the firm has acted in accordance with $\S 1$ GWB, 100\% means a clear, serious violation. 50\% should be chosen for less serious violations.

The pecuniary profit is measured according to the profit of the respective firm and the duration of the agreement. However, if the agreement has been in place for more 
than five rounds, the penalty will only be applied to the profits of the last five rounds. Previous rounds are included in the calculation of the penalty, but will not be punished themselves. You, in the role of the competition authority, nevertheless enter the entire duration of the cartel; the computer program proportionally calculates the penalties for the last five rounds.

Your payment as an competition authority depends on the consistency of your penalty decisions with those of a real competition law expert. After today's experiment, in the same way as you do today, this expert (a licensed lawyer specialized in competition law) will see the chat messages and prices and will assess the extent to which they contain violations of $\S 1$ GWB. You will receive 900 points for each match between your decision and the expert's decision. You will also receive 900 points if you have correctly specified the duration of a possible agreement. Since you make four decisions for each penalty decision (one for each of the three firms and one for the total duration of the agreement), you can earn up to 3600 points. You will only receive points if you make exactly the same decision as the expert, otherwise (e.g. if you impose a $50 \%$ penalty on a firm and the expert would impose 100\%) you will not receive any points for this partial decision. At the end, the average score of all rounds in which you were able to impose penalties is determined. This then determines your payment, which we will transfer to your bank account within 2 to 3 weeks. If there is no audit during the entire experiment, you will receive a fixed bank transfer of 15 euros in addition to your cash payment of 10 euros.

You have 3 minutes for each of your penalty decisions. If you do not specify the height of the penalty during this time, you will not receive any payment for your judgment and the computer program will assume for the calculation of the firms' profits that you have not imposed any penalties. Please remember to submit your decision at the end by clicking the OK button.

The active initiation of an audit by a firm leads to the possibility that that firm is exempted from its punishment. If only one firm has initiated the audit, that firm will automatically receive full amnesty. If two or three firms have initiated an audit, the penalty will only be waived for the firm that first initiated the audit. This exemption will also be automatically implemented by the computer program, if necessary, and will not be relevant to your penalty decisions.

After each round, the firms are informed about their own price, their profit and, if applicable, their penalty. In addition, each firm is informed about the prices set by the other two firms in the current round and, if applicable, their penalties. The firms will 
also be informed on whether a firm has initialized an audit by the competition authority and has thus received an exemption of its penalty.

From the 25th round on, a random mechanism decides in each round whether the experiment ends with the last round completed. With a probability of $33.3 \%$ (i.e. in an average of 1 out of 3 cases) the experiment ends with the last round completed. With a probability of $66.7 \%$ (i.e. in 2 out of 3 cases) another round takes place. In addition, it is ensured that the experiment does not last longer than 2 hours and 30 minutes.

Directly after the experiment you will receive 10 euros in cash. Your additional earnings from the experiment will be transferred to your bank account. Please enter your name and address as well as your bank details in the form and sign it. (You are welcome to fill in the form during the experiment, if you have nothing to do on the screen.)

If something is not clear to you, please give a clear hand signal. We will then come to your seat.

After the experiment we will ask you to fill out a short questionnaire ${ }^{25}$ on the computer. You will then receive your payment.

\footnotetext{
${ }^{25}$ The questionnaire asked for some statistical information which we use for the administration of the computer laboratory. Otherwise, we did not use it for the evaluation of the data.
} 


\section{C.3 Assistance for Authorities - How does the expert punish?}

What counts as an agreement?

- If a firm explicitly suggest a price above 3 and then charges this price, the firm gets a $100 \%$ penalty.

- Convoluted descriptions of prices are punished in the same way as if the corresponding price was given as a number.

- Agreements on prices not higher than 3 do not distort competition and therefore do not count as an agreement.

- If a firm doesn't write anything in the chat (but of course can read what the others write) it can still be punished. The amount of the penalty depends on the price and can be up to $100 \%$, e.g. if the other two firms make a clear agreement and this firm sets exactly the price agreed by the other two firms over a long period of time.

- If the firms make an agreement that no one will abide by afterwards, there will be no penalty.

- Prices above 3, which have come about without any agreement, cannot be punished.

For determining the duration:

- For determining the duration of a cartel, all rounds in which the agreement was visibly effective in the prices count.

- If a company receives a $50 \%$ penalty for part of the total duration of the cartel and a $100 \%$ penalty for the remainder of the total duration, then the amount of the penalty that applies for a longer period will apply for the total duration (because the computer program does not allow for further gradation).

- If a firm joins an agreement already in place between the two other firms at a later round (or leaves the agreement earlier than the others), the longer overall duration of the cartel still applies to it. In order to prevent the fine from becoming unreasonably high, the amount of the fine can then be adjusted accordingly. (Example: Anyone who was involved in a $100 \%$ agreement in 5 out of 10 rounds receives a $50 \%$ penalty for the duration of 10 rounds.)

- If, after a penalty, prices remain at the same level as before the audit, a penalty may be imposed again at a later audit, even if there has been no new agreement. 